\title{
Gynaecological malignancies in Azare, North-East Nigeria: an assessment of types, stage at presentation and treatment affordability
}

\author{
Muhammad B. Aminu ${ }^{1 *}$, Sanusi M. Ibrahim², Nasiru A. Garba³, Nasiru I. Umar³, \\ Nighat Khan ${ }^{3}$, Hadiza A. Usman²
}

\begin{abstract}
${ }^{1}$ Department of Obstetrics and Gynaecology, Abubakar Tafawa Balewa University Teaching Hospital Bauchi, Bauchi State, Nigeria

${ }^{2}$ Department of Obstetrics and Gynaecology, University of Maiduguri Teaching Hospital, Maiduguri, Borno State, Nigeria

${ }^{3}$ Department of Obstetrics and Gynaecology, Federal Medical Centre, Azare, Bauchi State, Nigeria
\end{abstract}

Received: 25 February 2020

Accepted: 30 March 2020

\section{*Correspondence:}

Dr. Muhammad B. Aminu,

E-mail: aminubaffahmuhammad@gmail.com

Copyright: (c) the author(s), publisher and licensee Medip Academy. This is an open-access article distributed under the terms of the Creative Commons Attribution Non-Commercial License, which permits unrestricted non-commercial use, distribution, and reproduction in any medium, provided the original work is properly cited.

\section{ABSTRACT}

Background: In many parts of the world, presentations for most gynecological cancers are late; this makes treatment difficult due to the cost of chemotherapy or radiotherapy which form the bedrock for cure or palliation. Objective of this study was to determine the types, stage at diagnosis, affordability of care and outcome of treatment of gynaecological cancers in Federal Medical Centre Azare, Bauchi State, Nigeria.

Methods: All cases of gynaecological cancers seen over a ten-year period, from 1st January, 2003 to 31st December, 2012 were reviewed retrospectively. The number of all gynaecological cases seen during the period was also extracted.

Results: Gynaecological cancer cases accounted for $11.84 \%$ of 8,642 gynaecological cases seen during the period of study. The mean age and parity of the women were $42 \pm 5 \mathrm{SD}$ years and $5 \pm 1 \mathrm{SD}$ respectively. Cervical cancer accounted for $55 \%$, ovarian cancer $30 \%$, endometrial cancer $6 \%$, choriocarcinoma $5 \%$, secondaries/ cancers of undetermined origin were $4 \%$. Ninety-two percent presented with advanced stage of diseases. Only $25.3 \%$ could afford the cost of full treatment, and $8.4 \%$ attained cure of their disease. The modalities of treatment available were surgery and chemotherapy.

Conclusions: Cervical and Ovarian Cancers remain the leading types of gynaecological cancers in our environment and late presentations are frequent occurrence. Late presentation and unaffordability of treatments are major challenges associated with the management of these patients. Early presentation and funding mechanisms for gynaecological cancers are keys to improved cure rate and reduced mortality.

Keywords: Gynaecological malignancies, Late presentation, Treatment affordability

\section{INTRODUCTION}

Malignancies are serious public health issues with no age or gender preference. Globally they are the second cause of mortality. ${ }^{1,2}$ The world health organization (WHO) estimated that by the year 2020, about 16 million new cases of cancers will be diagnosed, with more than two- third of them occurring in developing countries and by 2035 , mortality from cancers will increase by close to 70 percent. ${ }^{3,4}$ This figure is even worst in Africa where the lifetime risk of dying from cancer every year is twice that of the developed nations. ${ }^{5}$ In Nigeria and some parts of Africa, the burden of Malignancies is generally under reported mainly due to poverty and poor record system, 
inadequate infrastructure, shortages of human resource and diagnostic facilities. It is widely acknowledged that the majority of commonly occurring cancers are preventable or curable if detected early, but the facilities or screening tools for detection are not readily available and even where they are available, they are not easily accessible and affordable. ${ }^{6}$ Across all the geopolitical zones of the country, only sparse data are available, but the general assumption is that, cervical cancer is ranked second among all the cancers and is the most common female genital cancer accounting for a larger percentage of mortality among Nigerian women in their most prime years. ${ }^{7}$ This is followed by Ovarian and endometrial cancers. ${ }^{8}$ Choriocarcinoma and vulval cancer are the least common forms. ${ }^{8}$

Available statistics indicated that, despite these occurrences, a regional variation exists globally and locally in the distribution of cancers in women, with cancer of the cervix commoner in the Northern Nigeria while ovarian cancers are seen more in the Southern part of the country, largely due to their life style and cultural practices. $^{9}$

Cancer treatments are commonly associated with lots of challenges ranging from diagnosis to cost of treatments. In Nigeria and other developing nations, the presentation for most gynaecological cancers are late or advanced; this makes treatment difficult due to the cost of chemotherapy or radiotherapy which forms the bedrock of cure or palliation. Therefore, poverty plays a major role in accessibility and affordability of cancer treatment, especially in Nigeria where it remains significant at 46.4.1\% despite massive wealth and a huge population to support commerce, a well-developed economy, and plenty of natural resources such as oil. ${ }^{10}$ Furthermore, where the funds for treatment are available, the long waiting period for therapy is an important hinderance. ${ }^{11,12}$ In some cases, the chemotherapy administered is erratic or incomplete due to inability of the patients to fully mobilize funds to sustain the treatment, making the final outcome of the intervention less effective and resulting in high rates of mortalities. ${ }^{12}$

The study aimed to determine the types, affordability of treatment and stages at presentation, of gynaecological cancers in Federal Medical Centre Azare, Bauchi State, Nigeria. The findings will help to assess the magnitude of gynaecological malignancies in our tertiary institutions and equally assist in opening the gaps created by out-ofpocket expenses in the management of gynaecological cancers in our region. Hence, it will assist in proper health planning towards ameliorating the effect of the disease.

\section{METHODS}

It was a retrospective study, carried out at the departments of obstetrics and gynaecology and histopathology of the Federal Medical Centre Azare,
Bauchi State, Nigeria from January $1^{\text {st }}, 2003$ to December $31^{\text {st }}, 2012$. Federal Medical Centre Azare is the second Apex tertiary hospital in Bauchi state and covers about 10 local government areas and the neighboring states of Yobe and Jigawa. Ethical approval was obtained from the research and ethics committee of the institution. All the records of patients that had histologically confirmed gynecological cancers seen in the units over the ten-year period were retrieved and included in the study. Characteristics such as types of genital cancers, stage of the cancers, treatment affordability and disease outcome were recorded. The details were noted down on a proforma.

\section{Statistical analysis}

Data analysis was done using IBM SPSS software version 20.0 (New York, 2011) and results were reported in Pie and Bar charts as illustrated below.

\section{RESULTS}

Gynaecological cancer cases accounted for 1,023 (11.84\%) of 8,642 gynaecological admission seen during the period of study. The mean age and parity of the women were $42 \pm 5$ years and $5 \pm 1$ respectively.

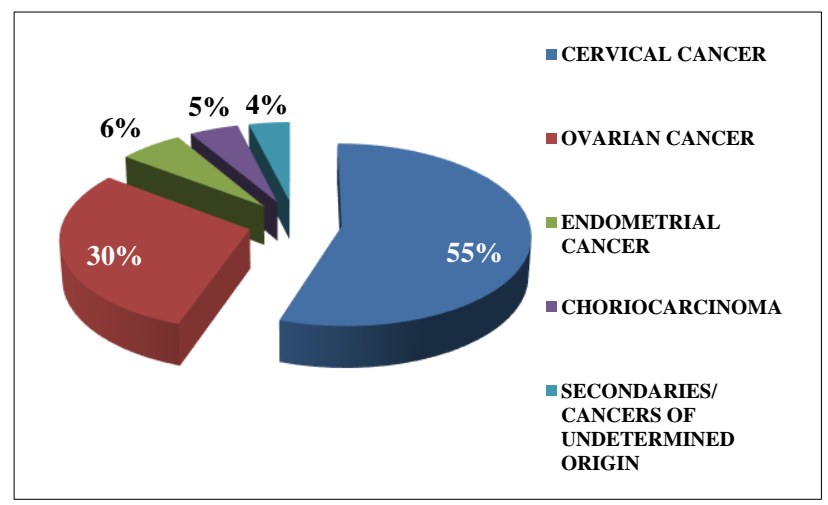

Figure 1: Distribution of gynaecological cancers $\mathrm{N}=\mathbf{1 , 0 2 3}$.

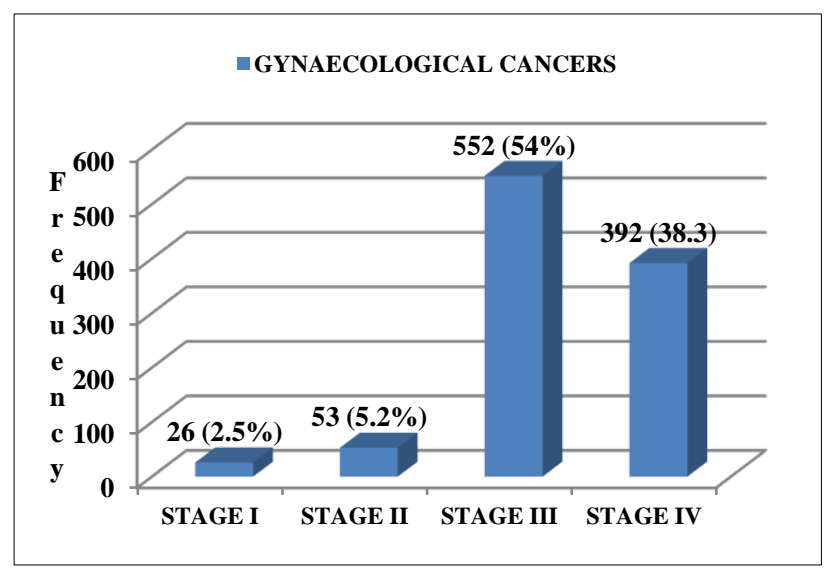

Figure 2: Distribution of cancer cases by stages at diagnosis $(\mathrm{N}=1,023)$. 
Cervical cancer accounted for $563(55 \%)$, ovarian cancer $307(30 \%)$, endometrial cancer $61(6 \%)$, choriocarcinoma $51(5 \%)$, secondaries/ cancers of undetermined origin 41 (4\%) (Figure 1). Ninety-two percent presented with advanced stage of diseases (Figure 2). Only $25.3 \%$ could afford the cost of full treatment, and $8.4 \%$ attained cure of their disease (Figure 3 and 4). Seven hundred and eleven $(69.5 \%)$ patients were able to afford partial treatment of their disease. The modalities of treatment available were surgery and chemotherapy.

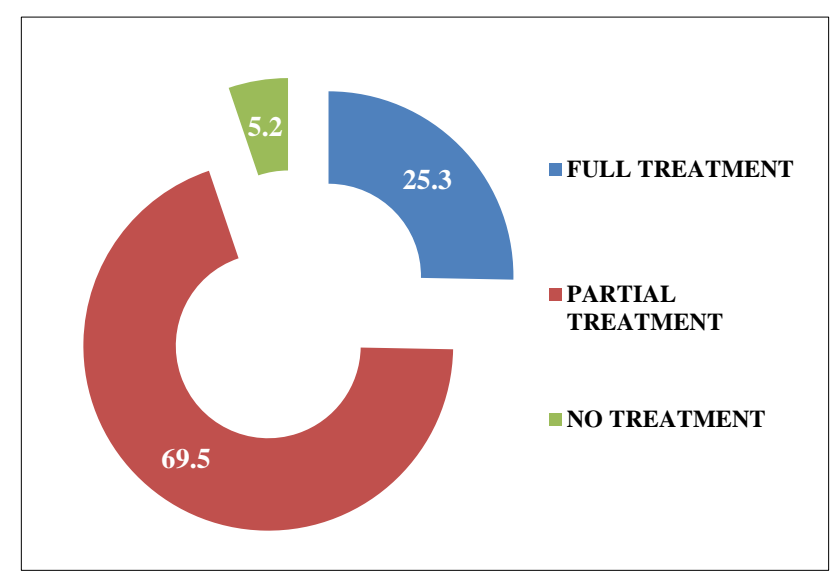

Figure 3: Percentage distribution of cancer cases by treatment affordability $(\mathrm{N}=1,023)$.

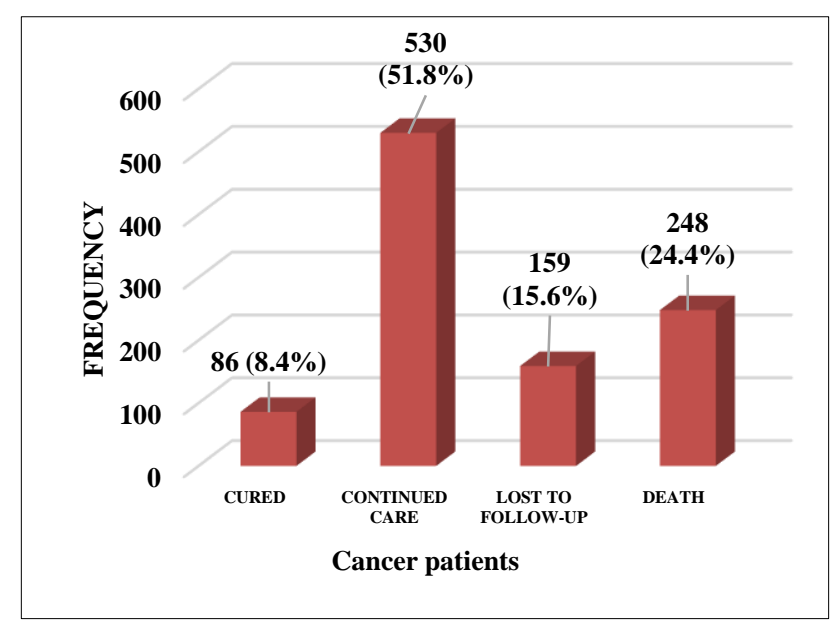

Figure 4: Treatment outcome and mortality associated with cancers.

\section{DISCUSSION}

The burden of cancers especially of the female genital tract remains high. A considerable number of gynaecological patients had gynaecological cancers $(11.84 \%)$ in this study population, making cancer a common gynaecological diagnosis. This rate concurs with findings from other parts of Nigeria which revealed high rates of gynaecological malignancies. ${ }^{8,13,14}$ Unlike in this environment, the overall burden of cancers in many developed countries has reduced. ${ }^{12}$ Therefore, this study only supports the wide gaps in cancer screening and management that are known to exist in developing countries.

Cervical cancer leads as the most common genital cancers, corroborating the fact that it is the second most common female cancer and commonest genital cancer in the low resource nations. 5 Ovarian cancers as observed in the study was the second commonest, accounting for $30 \%$ of all the genital cancers seen over the period. Again, this is in consonance with many reports from developing countries where cervical and ovarian cancers have remained the two leading types of genital cancers. ${ }^{15,16}$ While the reason for increase cervical cancer rate could be poor uptake of available screening methods to detect precancerous lesions, that of ovarian cancer could be socio- demographic change in lifestyle typical of industrialized countries. Endometrial, choriocarcinoma and other secondary cancers were the least common forms, a finding similar to the pattern in many other regions in the country. ${ }^{17}$

Carcinoma of the cervix is largely a preventable condition and among the cardinal principles of cancer management is early detection which when instituted may lead to appropriate therapy resulting in cure, but the trend observed from this study was that of late presentation with more than two-third of the patients diagnosed at stages III and IV and barley less than $10 \%$ at early stage (Figure 2). This is in sharp contrast to the study in Morocco where a significant number of the clients were seen and diagnosed at stage II of the disease, but similar to a study in South east, Nigeria where close to half of the patients presented in stage III and IV. ${ }^{18,19}$ Factors that enable late presentation and diagnosis of cancers reside very much in low income countries such as Nigeria. These enablers include lack of basic screening tools, poverty, defective infrastructures, illiteracy, and lack of trained human resource for health. ${ }^{5,19}$ For instance, it is documented that only about $5 \%$ of the women at risk of cervical cancers have been screened in sub Saharan Africa. ${ }^{20}$ Although ovarian and endometrial cancers as well as choriocarcinomas have no screening tools like cervical cancers, a presumptive screening can be done from clinical history, physical examination and supportive investigations such as ultrasound scan and assay of tumour markers to screen at risk group. Doing this will go a long way in early detection and thus reducing late presentation.

In addition, the absence of health insurance scheme especially for the elderly may be a reason for the delay in presentation for most cancers in the study region, and even where women have been enrolled in the insurance scheme, the majority of cancers and their treatments are not covered by the scheme in Nigeria, and some middle income countries. ${ }^{21}$ The consequences of this noncoverage is encouragement of out of pocket medical bill payments and poor health seeking behaviours, forcing the patients not to present during the early phase of the disease until they become incapacitated and had to visit 
the clinic even without having the required fund for care. On a general note, there is maldistribution of health facilities and cancer diagnostic equipment in Nigeria and many parts of developing countries, with the urban centres favored more than the rural ones, making cancer care services inaccessible.

Although available data on cancer research are hospital based, it is obvious that cancer incidence is rising in Nigeria. ${ }^{2,9}$ In this study, it was observed that $8.6 \%$ on the patient had cure from the disease, while $51.8 \%$ had continued follow up as at the time of data collection. The $15.6 \%$ patients lost to follow up could be due to poverty and level of health awareness in the study area. Deaths, poverty, illiteracy and side effects of cytotoxic are known reasons for loss to follow-up. Many of these patients who were lost to follow up initially had erratic courses of treatment due to difficulty in funding their treatment. Erratic courses of cancer chemotherapy in many instances can lead to relapse, making cure difficult and increasing morbidity and mortality.

This study has provided us with a baseline data about the most prevalent gynaecological malignancy in this region, which will help us modify and strengthened our public enlightenment approach on the diagnosis and treatment of the major cancers identified. A cross-sectional or prospective study aimed at exploring the possible reasons for some findings, like late presentation, missed therapy and loss to follow-up is advocated.

\section{CONCLUSION}

Cervical, ovarian and endometrial cancers remain the leading types of gynaecological cancers in our environment and late presentations are frequent occurrence. Unfortunately, not all the patients diagnosed with the conditions could foot the bills of their therapy, with many lost to follow up. Early presentation at the hospital and availability of cost-effective treatment regimens and funding mechanism for cancers are keys to improved cure rate and reduced mortality.

\section{Funding: No funding sources}

Conflict of interest: None declared

Ethical approval: The study was approved by the Institutional Ethics Committee

\section{REFERENCES}

1. Fitzmaurice C, Dicker D, Pain A, Hamavid H, Moradi-Lakeh M, MacIntyre MF, et al. The global burden of cancer 2013. JAMA Oncol. 2015;1(4):50527.

2. Johnson LG, Armstrong A, Joyce CM, Teitelman AM, Buttenheim AM. Implementation strategies to improve cervical cancer prevention in sub-Saharan Africa: a systematic review. Implement Sci. 2018;13(1):28.
3. Adekunle OO, Marliyya ZS, Sunday AA, Abimbola KO, Richard T, Habiba I, et al. The pattern of carcinoma of the vulva in Zaria, Northern Nigeria. Nigerian J Basic Clin Sci. 2016;13(1):46.

4. Globocan 2012 V1.0 Cancer Incidence and Mortality Worldwide: IARC Cancer Base No. 11, 2013. Available at: http://globocan.iarc.fr/Default.aspx. Accessed on $10^{\text {th }}$ December 2017.

5. Catarino R, Petignat P, Dongui G, Vassilakos P. Cervical cancer screening in developing countries at a crossroad: emerging technologies and policy choices. World J Clin Oncol. 2015;6(6):281-90.

6. World Health Organization, World Health Organization. Reproductive Health, World Health Organization. Chronic Diseases, Health Promotion. Comprehensive cervical cancer control: a guide to essential practice. World Health Organization; 2006.

7. Mandong BM, Manasseh AN, Ayuba DM, Olugbenga SA, Emmanuel I, Kwaghe BV, et al. Burden of cancer in plateau state, central nigeria: a 27-year report from a tertiary hospital-based cancer registry. J Adv Med Medi Res. 2018:1-1.

8. Usman HA, Audu BM, Bukar M, Mayun A, Ibrahim SM. A five-year review of female genital tract malignancies at the University of Maiduguri Teaching Hospital, Maiduguri, Nigeria. Bo Med J. 2017;14(2):152-8.

9. Sowunmi A, Alabi A, Fatiregun O, Olatunji T, Okoro US, Etti AF. Trend of cancer incidence in an oncology center in Nigeria. West African $\mathbf{J}$ Radiol. 2018;25(1):52.

10. World Poverty Clock. World Data Lab. 2018. Available at: https://worldpoverty.io/index.html. Accessed 22 ${ }^{\text {nd }}$ August 2019.

11. Ginsburg O, Bray F, Coleman MP, Vanderpuye V, Eniu A, Kotha SR, et al. The global burden of women's cancers: a grand challenge in global health. The Lancet. 2017;389(10071):847-60.

12. Cheng ES, Weber M, Feletto E, Smith MA, Yu XQ. Cancer burden and control in Australia: lessons learnt and challenges remaining. Ann Cancer Epidemiol. 2018;2.

13. Yakasai IA, Ugwa EA, Otubu J. Gynaecological malignancies in Aminu Kano Teaching Hospital Kano: A 3 year review. Nig J Clin Pract. 2013;16:636.

14. Umeobika JC, Ikeako LC, Ezenyeaku CT, Ezenyeaku CT, Ezebialu UI, Ojiyi EC. Gynaecological malignant tumours at imo state university hospital Orlu South Eastern Nigeria. Afrimedic J. 2018;(6):52-8.

15. Usman HA, Audu BM, Kullima AA, Isa B, Ibrahim SM. A continuing tragedy of maternal mortality in a rural referral centre in Northeast Nigeria: A wake-up call. Trop J Obstet Gynaecol. 2018;35(1):18-24.

16. Usman HA, Audu BM, Ibrahim SM, Bukar M, Pindiga HU. Pattern of cancers at a rural referral centre in North-Eastern Nigeria. Bo Med J. 2018;15(1): 21-8. 
17. Okeke TC, Onah N, Ikeako LC, Ezenyeaku CC. The frequency and pattern of female genital tract malignancies at the University of Nigeria Teaching Hospital, Enugu, Nigeria. Ann Med Health Sci Res. 2013;3(3):345-8.

18. Ouasmani F, Hanchi Z, Haddou Rahou B, Bekkali R, Ahid S, Mesfioui A. Determinants of patient delay in seeking diagnosis and treatment among Moroccan women with cervical cancer. Obstet Gynecol Inter. 2016;2016.

19. Eze JN, Emeka-Irem EN, Edegbe FO. A six-year study of the clinical presentation of cervical cancer and the management challenges encountered at a state teaching hospital in southeast Nigeria. Clinical Medicine Insights: Oncol. 2013;7:CMO-S12017.

20. Sankaranarayanan R, Budukh AM, Rajkumar R. Effective screening programmes for cervical cancer in low- and middle-income developing countries. Bull World Health Organ. 2001;79:954-62.

21. Aggarwal A, Unger-Saldaña K, Lewison G, Sullivan $\mathrm{R}$. The challenge of cancer in middle-income countries with an ageing population: Mexico as a case study. E Cancer Med Sci. 2015;9:536.

Cite this article as: Aminu MB, Ibrahim SM, Garba NA, Umar NI, Khan N, Usman HA. Gynaecological malignancies in Azare, North-East Nigeria: an assessment of types, stage at presentation and treatment affordability. Int J Reprod Contracept Obstet Gynecol 2020;9:1895-9. 